\title{
FILM ANIMASI 2 DIMENSI, “JACK THE CHICKEN!"
}

\author{
Ari Bakkas Pratama ${ }^{1}$, Mahendradewa Suminto $^{2}$ dan Andri Nur Patrio ${ }^{3}$ \\ ${ }^{1}$ Program Studi Animasi, Fakultas Seni Media Rekam, Institut Seni Indonesia Yogyakarta \\ aribakkaspratama@gmail.com \\ ${ }^{2}$ Program Studi Animasi, Fakultas Seni Media Rekam, Institut Seni Indonesia Yogyakarta \\ mahendrads@gmail.com \\ ${ }^{3}$ Program Studi Animasi, Fakultas Seni Media Rekam, Institut Seni Indonesia Yogyakarta \\ andrinurpatrio@gmail.com
}

\begin{abstract}
Abstrak
Film animasi berjudul "Jack The Chicken!" bercerita tentang seekor ayam bernama Jack yang merasa bosan dan tidak bersyukur dengan apa yang diberikan oleh majikannya. Animasi ini memiliki pesan untuk selalu bersyukur dengan apa yang didapat. Film animasi ini berdurasi kurang lebih 3 menit, dengan desain karakter yang simple, serta background dan backsound yang mendukung setting serta adegan dalam film ini, mengingat dalam film ini tidak ada dialog di dalamnya. Target audience untuk film animasi ini adalah anak - anak hingga dewasa. Film ini dibuat dengan teknik animasi dua dimensi (2D) di mana hampir seluruh prosesnya dikerjakan secara digital. Hal tersebut dilakukan untuk memudahkan proses pembuatan film, terutama untuk menyingkat durasi pengerjaan. Proses pengerjaan secara manual tetap dilakukan terutama pada tahapan awal seperti penjaringan ide dan desain karakter.
\end{abstract}

Kata kunci : Animasi 2D, Ayam, Digital Drawing

\begin{abstract}
Animated movie "Jack The Chicken" tells story about a chicken named Jack that bored and ungrateful with anything that are given by his master. This animation tells the audiences about being grateful for everything they've got. This animation video has three minutes duration with simple character design. This animated movie setting and scenes are largely supported by its background and backsound because it has no dialogues. This movie was made with $2 D$ technique where most of the creation processes were done digitally. These digital processes were done to make the works easier and shorten the duration of the works. Manual work progress also had been done especially on early stages of creation e.g. idea developing and character design.
\end{abstract}

Keywords: 2D Animation, Chicken, Digital Drawing 


\section{Pendahuluan}

Manusia dan hewan merupakan makhluk yang selalu memiliki keterkaitan dan interaksi. Tidak sedikit manusia menjadikan hewan peliharaan sebagai teman dalam hidupnya. Memiliki hewan peliharaan adalah hobi tersendiri karena tidak semua orang memiliki keinginan untuk menyayangi dan merawatnya. Dengan memelihara hewan manusia dapat melepas stress dan menjadikan hewan peliharaan sebagai teman untuk disayangi. Hewan yang paling umum untuk dipelihara diantaranya ayam, anjing, kucing, dan burung.

Di samping keterkaitan antara manusia dan hewan sebagai teman dan penghilang stress, beberapa hewan justru dimanfaatkan untuk bahan pangan manusia atau biasa disebut ternak. Hewan-hewan ternak yang kerap dijumpai seperti sapi yang diambil susunya, kambing yang diambil dagingnya, dan ayam yang diternakkan untuk diambil daging dan telurnya. Ayam merupakan salah satu hewan yang paling mudah diternak, karena ayam merupakan pemakan segala atau Omnivora. Jenis ayam yang sering dipelihara pada umumnya adalam ayam kampung, Film animasi “Jack The Chicken!” memiliki cerita tentang seekor ayam yang diperlihara namun ia merasa bosan dan tidak bersyukur dengan makanan yang diberikan oleh majikannya, sifat ayam ini merupakan bentuk dari sifat manusia yang dipersonifikasikan pada ayam. Di mana terkadang manusia tidak memiliki kepuasan dan selalu ingin yang lebih. Hal inilah yang menjadi latar belakang dan ide cerita dari film animasi 2D berjudul "Jack The Chicken!".

Berdasarkan latar belakang di atas dapat dirumuskan permasalahan yang akan diselesaikan yaitu menciptakan film animasi 2D “Jack The Chicken!” menjadi satu film yang utuh.

\section{Tujuan}

Tujuan dari penciptaan karya film animasi "Jack The Chicken!" yaitu :

1. Memberikan sebuah hiburan kepada penonton melalui film animasi

2. Sebagai pengalaman dan untuk menambah wawasan dalam berproduksi film animasi 2D.

3. Menyampaikan pesan kepada penonton dengan memberikan alur cerita yang tidak rumit dan mudah dimengerti. 


\section{Target Audien}

Target audien untuk film animasi ini adalah :

1. Geografis : Indonesia dan Internasional

2. Demografis :

Usia : 10 tahun keatas (remaja)

Jenis kelamin $\quad$ : Laki-laki dan perempuan

Pendidikan : : Dari latar pendidikan apapun

Status sosial : Semua kalangan

\section{Indikator Capaian Akhir}

Capaian hasil akhir dalam proses pembuatan film animasi dengan teknik 2 Dimensi ini memiliki indikator-indikator tahapan sebagai berikut:

\section{Penciptaan ide}

Ide penciptaan karya ini terinspirasi dari ayam sebagai hewan ternak, dan memiliki sisi keunikan tersendiri dalam tingkah laku dan makanan yang dikonsumsi.

\section{Pra Produksi :}

Pra-Produksi merupakan proses persiapan dalam sebuah produksi auditif-visual. Tahap-tahap persiapan pada Pra-Produksi antara lain :

\section{a. Penulisan Cerita}

"Jack The Chicken!" bercerita tentang seekor ayam yang bosan dengan makanan yang diberikan oleh majikannya. Hal tersebut membuat si ayam masuk ke dalam hutan untuk mengambil buah yang berukuran besar, kemudian berebut dengan seekor Bekantan (speises monyet endemic Kalimantan) yang juga menginginkan buah tersebut.

\section{b. Riset dan Concept film}

Riset yang dilakukan dalam pembuatan film dimulai dari memahami karakteristik ayam sampai dengan memahami setting tempat atau lokasi untuk divisualkan kembali ke kedalam film animasi 2D. 
Selanjutnya penulis mengkonsep karakteristik seekor ayam menjadi karakter yang menarik untuk sebuah film animasi. Dilanjtkan dengan mengkonsep latar tempat atau setting pada film animasi.

\section{c. Design character}

Dalam pembuatan desain karakter dilakukan berbagai macam tahap seperti konsep, sketsa, dan kemudian merancangnya mulai dari model sheet dan expression sheet sebagai acuan dalam proses animating.

\section{d. Storyboard}

Storyboard dibuat dengan teknik digital guna mempercepat proses praproduksi film agar langsung bisa dibuat key animate di software Paint Tool Sai 1.1 dan kemudian langsung ke proses animating di software Toon Boom Pro 8.1.

\section{Produksi :}

Produksi adalah proses inti dalam pembuatan film animasi, proses ini dilakukan setelah tahap praproduksi selesai. Berikut adalah beberapa tahap yang dilakukan dalam proses produksi :

\section{a. Background/ Environment}

Pembuatan background dilakukan dengan menggunakan teknik digital dari proses sketsa hingga painting (coloring) dan kemudian akan disatukan dengan animatic lewat software Paint Tool Sai 1.1.

\section{b. Dubbing}

Proses rekaman untuk mengisi suara karakter dan suara untuk mengisi latar belakang atau setting pada film animasi untuk mendukung sebuah nuansa dalam film.

\section{c. Sound Effect}

Sound effect menggunakan musik ilustrasi dengan memadukan alat musik Sape dari Kalimantan, mengingat setting film ini adalah daerah Kalimantan. Selain itu juga menggunakan beberapa efek pendukung seperti suara benda jatuh, dll. 


\section{d. Key Animation}

Pembuatan key animation adalah bentuk pengembangan dari storyboard yang telah dibuat, dan menjadi gerakan kunci dalam membuat gerakan di film animasi.

\section{e. In Between}

Gerakan yang dibuat di antara gerakan kunci, dalam proses pembuatan in between menggunakan software Toon Boom Studio 8.0 dengan frame rate $24 f p s$

\section{Pasca Produksi :}

Pascaproduksi merupakan tahapan akhir atau proses finishing, Pascaproduksi berlangsung setelah produksi selesai, Berikut adalah tahapantahapan dari pascaproduksi:

\section{a. Editing}

Proses editing merupakan penggabungan antara shot animasi yang telah dibuat di tahap sebelumnya, proses ini juga merupakan penggabungan antara music dan sound effect

\section{b. Mastering and Render}

Tahap terakhir dalam pembuatan film animasi ini yaitu mengexportfile video dan audio yang telah disatukan ke dalam bentuk film utuh dengan format .mp4, kemudian dilakukan proses burning ke dalam DVD, dan kemudian dikemas dan diberi sampul.

\section{c. Display dan Merchandising}

Display karya dilakukan setelah film animasi selesai dibuat, dan merchandising mencangkup media pengenalan dan promosi seperti poster, stiker, dan media lainnya dan merchandising juga sebagai pelengkap untuk keperluan display karya pameran. 


\section{LANDASAN TEORI}

Pada era modern, pemanfaatan teknologi dapat menjadi solusi dalam berbagai pemecahan masalah seperti pada teknologi informasi. Dengan teknologi informasi, manusia dipermudah dalam memperoleh hal-hal yang dibutuhkan. Menurut Daniel Chandler dan Rod Munday dalam buku A Dictionary of Media and Communication (2011, hal. 211), bahwa teknologi informasi secara umum bersinonim dengan komputer dan jaringan komputer namun lebih luas dalam hal perancangan berbagai teknologi yang digunakan untuk mengumpulkan, menyimpan, memproses, dan/atau mendistribusikan informasi secara elektronik. Salah satu yang sering kita jumpai dalam pendistribusian informasi masa kini dengan menggunakan animasi.

Animasi telah dikenal bertahun-tahun lalu dan banyak mengalami banyak perkembangan sesuai perubahan zaman. Animasi berasal dari bahasa latin yaitu anima yang berarti jiwa, hidup, semangat, dalam Kamus Lengkap InggrisIndonesia (1997) berarti menghidupkan. Menurut Hendi Nugroho (2011, hal. 17), animasi adalah pemberian gerak ke objek atau karakter untuk dapat memberikan kesan hidup pada objek atau karakter. Secara umum animasi merupakan kegiatan menghidupkan, menggerakan benda mati agar terkesan hidup. Asal mula teknik animasi adalah keinginan manusia untuk membuat gambar yang hidup dan bergerak sebagai pengungkapan (expression) mereka, merupakan perwujudan dasar animasi yang hidup dan berkembang. Menurut Ibis (2002, hal. 183), menyatakan bahwa Animasi adalah sebuah proses merekam dan memainkan kembali serangkaian gambar statis untuk mendapatkan kembali sebuah ilusi pergerakan. Ada berberapa jenis animasi yang umumnya kita jumpai sehari-hari saat kita menonton televisi, mengakses smartphone, maupun di videotron jalan raya. Di antaranya ada animasi 2D (dua dimensi) dan 3D (tiga dimensi). Animasi 2D (dua dimensi) merupakan animasi yang secara visual tampak flat. Animasi 2D jika dikategorisasikan dari teknik pembuatannya terbagi menjadi dua, yaitu teknik manual dan digital. Teknik animasi manual atau yang biasa disebut dengan cellanimation adalah teknik pembuatan animasi yang paling tua usianya. Animasi 2D mengalami beberapa perkembangan dari yang dibuat secara manual menggunakan kertas hingga 
menggunakan bantuan komputer atau digital. Adanya computer membuat produksi animasi ini lebih mudah serta proses editing dapat dilakukan dengan lebih singkat.

Animasi 3D (3 dimensi) adalah animasi yang memiliki sifat kedalaman atau ruang pada objeknya, dengan menggunakan tiga sumbu $\mathrm{X}$, $\mathrm{Y}$, dan $\mathrm{Z}$ sebagai sumbu kedalaman. Objek yang dihasilkan dari animasi 3D bisa diputar sesuka hati menurut sumbunya.

\section{Tinjauan Karya}

Film animasi “Jack The Chicken!” mengambil referensi visual dari beberapa film. Referensi visual yang digunakan sebagai bahan studi dalam mendesain Dari segi background, karakter, serta unsur lain yang mendukung film animasi ini diambil dari animasi bertema hutan dan etnik. Seperti yang telah dijelaskan sebelumnya, film animasi “Jack The Chicken!" ber-setting di lingkungan hutan serta memiliki tema etnik yang khas seperti bentuk pohon, rumput dan lain-lain. Berikut adalah beberapa film animasi yang menjadi referensi penciptaan film animasi “Jack The Chicken!” :

\section{Pada Zaman Dahulu}

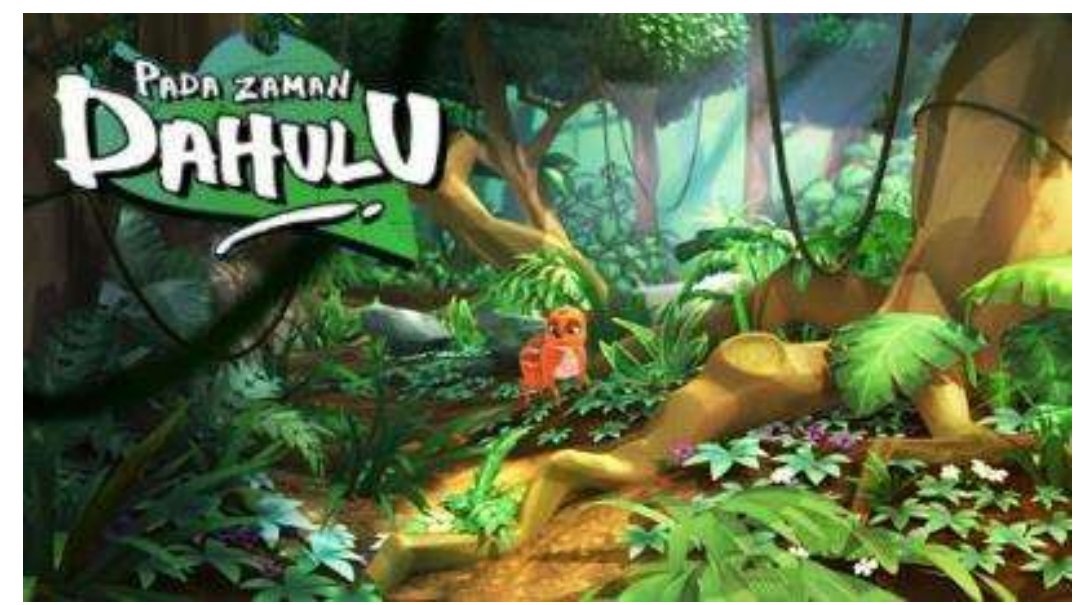

Gambar 1. Film Animasi Pada Zaman Dahulu (Wing, 2011)

Pada Zaman Dahulu adalah film produksi Les' Copaque Production yang rilis pada tahun 2011. Film ini menjadi referensi penulis karena terdapat banyak hewan yang divisualisasikan secara unik dengan karakteristiknya masing- masing. Film ini 
juga mengambil ber-setting di hutan yang sesuai dengan setting/latar dalam film "Jack the Chicken".

\section{Tak And The Power Of Juju}

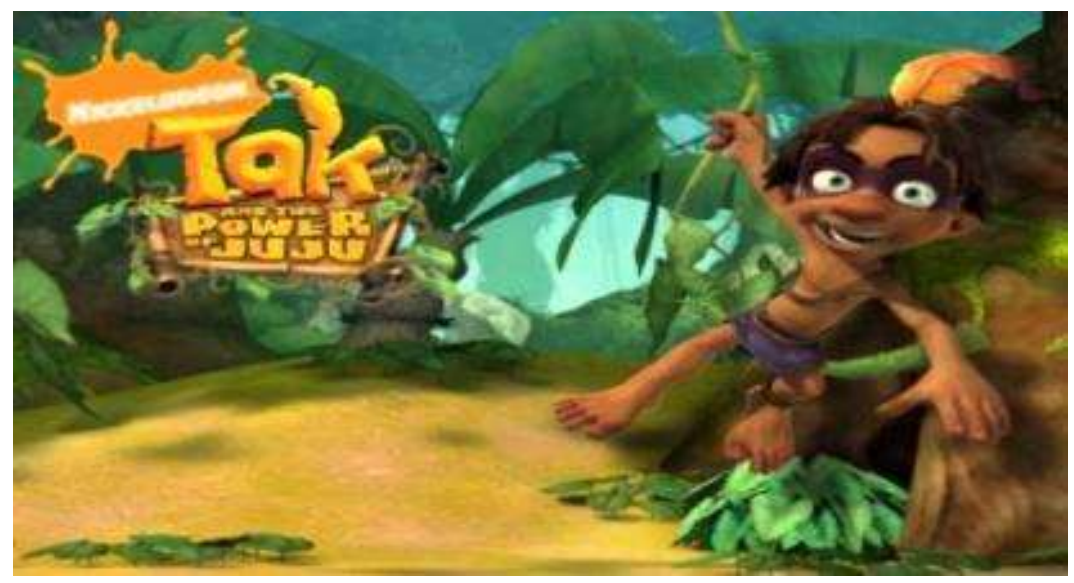

Gambar 2. Film Animasi Tak And The Power Of Juju (Trapazoid11, 2010)

Tak and The Power of Juju adalah film yang diproduksi tahun 2007 oleh Nicklodeon. Film ini menjadi referensi sekaligus acuan penulis, karena hampir sebagian besar setting film ini berada di hutan. Film ini memiliki setting hutan yang cukup unik mulai dari bentuk pepohonan, daun, serta tempat tinggal dari si karakter utama. Setting inilah yang akan digunakan oleh si penulis dalam membuat film animasi dengan menggabungkan antara konsep hutan yang lebat dan dipadukan dengan motif batik dari daerah Lampung.

\section{PERANCANGAN}

\section{Cerita}

\section{Tema}

Terinspirasi dari kebiasaan hewan ayam yang kerap mencari makan sembarangan. Terkadang bahkan memakan makanan yang tidak sewajarnya (bukan makanan yang sengaja diberikan oleh pemiliknya). Ide tersebut dikembangkan menjadi sebuah cerita tentang seekor ayam yang memiliki selera tertentu pada makanannya. Hal tersebut membuatnya menjadi ayam yang suka pilih-pilih makanan. 


\section{Sinopsis}

Di sebuah rumah yang bersebelahan dengan hutan, ada seorang kakek yang memiliki peliharaan seekor ayam bernama "Jack", ayam tersebut merasa bosan dengan makanan yang diberikan majikannya, Jack tidak merasa bersyukur dan malah membuang makanan yang diberikan oleh majikannya. Saat ia melihat ke arah hutan, ia melihat ada buah yang sangat besar di atas pohon, namun tidak bisa ia ambil karena berada pada pohon yang sangat tinggi. Kemudian cara yang ia pilih adalah dengan menunggu sampai buah itu jatuh. Saat buah itu terjatuh dari pohonnya, tiba tiba ada seekor bekantan (monyet Kalimantan) yang tiba tiba merebut buah itu dari Jack, mereka pun terlibat aksi kejar- kejaran sampai berujung pada perkelahian. Perkelahiaan tersebut dimenangkan oleh Jack, Jack berhasil mendapatkan buah tersebut. Namun saat ia ingin memakannya, buah itu tiba tiba berubah menjadi kupu kupu. Ternyata buah yang selama ini diidamidamkan olehnya bukanlah buah, melainkan kepompong yang berisi kupu kupu.

\section{Desain}

Pada film animasi “Jack The Chicken!” ada beberapa karakter yang berperan didalamnya. Berikut adalah penjelasan dari tiap karakter:

\section{Karakter}

\section{a. Jack}

Jack adalah karakter utama pada film animasi “Jack The Chicken!". Jack merupakan ayam hutan berumur 2 tahun yang dipelihara oleh seorang kakek. Jack adalah ayam jantan yang kurus dan kikuk. Badannya yang kurus mempersentasikan bahwa ia merupakan seekor ayam yang terlalu memilihmilih makanannya, tidak seperti ayam pada umumnya yang merupakan pemakan segala atau omnivora. 


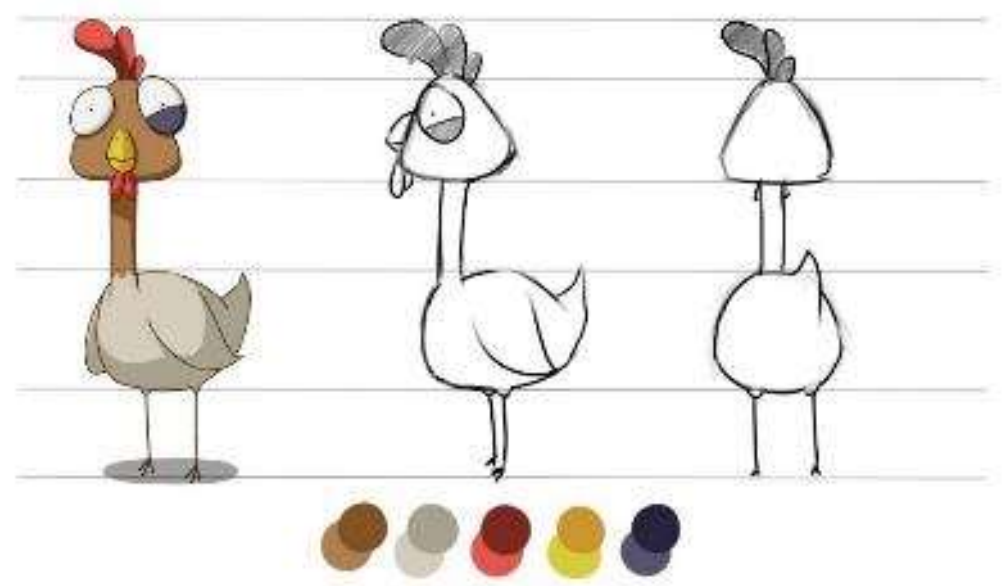

Gambar 3. Character Sheet Tokoh Jack

\section{b. Bekantan}

Karakter utama yang kedua merupakan seekor monyet Kalimantan atau yang biasa disebut Bekantan. Bekantan merupakan lawan main dari Jack, di mana bekantan pada film animasi "Jack The Chicken!” merupakan karakter yang merebut buah dari Jack. Bekantan merupakan binatang yang hanya ada di Kalimantan (endemik). Bekantan mempunyai ciri-ciri utama yang membedakan nya dari monyet lain, yaitu rambut berwarna coklat kemerahan dan hidung panjang dan besar yang hanya ditemukan di spesies jantan.

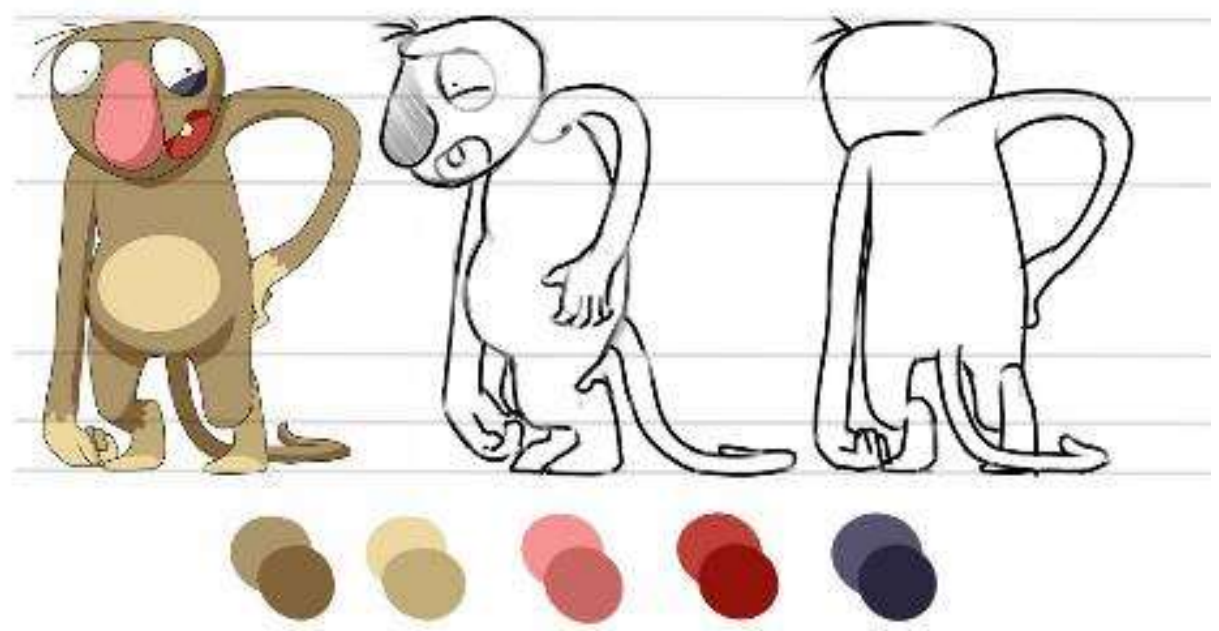

Gambar 4. Character Sheet Tokoh Bekantan

\section{c. Kakek}

Seorang kakek berumur kurang kebih 60 tahun ini adalah pemilik dari Jack, seekor ayam yang menjadi karakter utama dalam film “Jack The chicken!”. 
Karakter Kakek berperan sebagai karakter pendukung dalam film animasi ini. Di mana karakter ini hanya lewat dan memberi makan Jack.

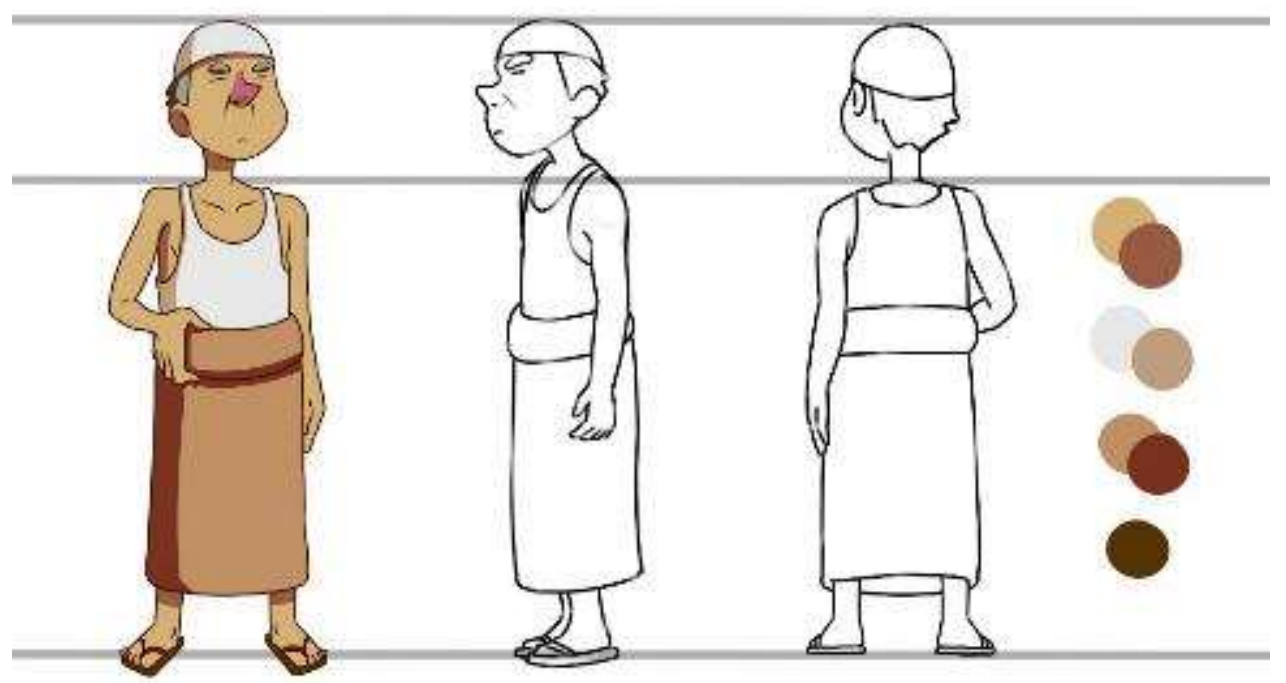

Gambar 5. Character Sheet Tokoh Kakek

\section{d. Kupu-kupu}

Karakter kupu-kupu merupakan karakter pendukung dalam film animasi “Jack The Chicken!'. Karakter kupu-kupu muncul pada bagian akhir dari film animasi ini.

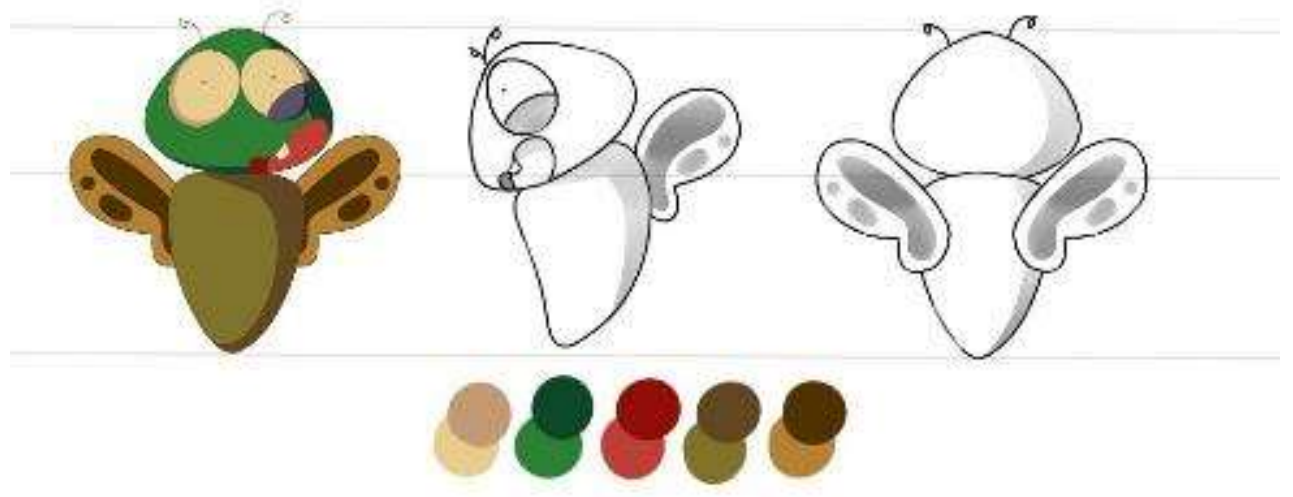

Gambar 3. Character Sheet Tokoh Kupu-kupu 


\section{Software}

Software yang digunakan adalah :

1. Toon Boom Studio 8.1

2. Paint Tool SAI 1.1

3. Adober Premiere CS6

4. Logic Pro $X$

5. Adobe After Effect

\section{Background Music}

Pembuatan film animasi “Jack The Chicken!” menggunakan Background Music yang dibuat sendiri dan disesuaikan dengan tema dan setting pada film animasi tersebut, di mana film animasi "Jack The Chicken!" bergenre komedi, dan bersetting di hutan Kalimantan.

\section{Pembahasan Proses Pembuatan Film}

\section{Preposisi}

Fase ini dimulai dengan pengenalan tokoh utama bernama Jack sedang berada di belakang rumah majikannya, tepatnya di dekat kandangnya. Tak lama kemudian, pemilik Jack yaitu si kakek lewat dan Jack beraksi meminta makan padanya. Rangkaian adega tersebut terangkai pada adegan di scene 2 cut 4 di mana terlihat pada gambar di bawah saat kakek sedang lewat dan Jack meminta makan kepada kakek dengan kamera Close Up kearah Jack. 


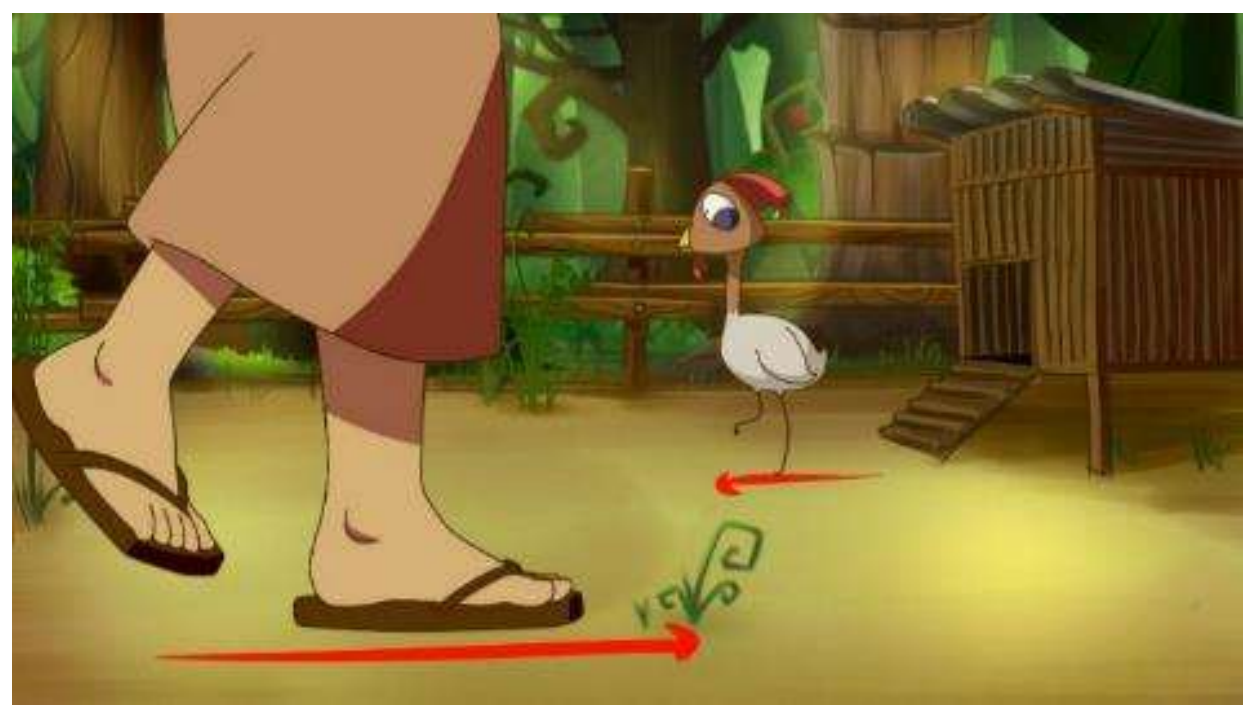

Gambar 4. Pengenalan Latar Tempat dan Suasana

\section{Konflik}

Konflik yang terjadi adalah ketika Jack sudah susah payah mengambil buah yang ada dipohon, dan ketika buah itu jatuh. Tiba tiba seekor bekantan langsung mengambil buah itu dari Jack.

\section{Resolusi}

Mereka kejar-kejaran di tengah hutan dan berujung pada perkelahian. Perkelahian tersebut pada akhirnya dimenangkan oleh Jack, Jack pun dengan berbangga hati ingin memakan buah tersebut ketika tiba-tiba buah yang dipegangnya meledak dan berubah menjadi Kupu-kupu. Ternyata buah yang selama ini ia kejar dan susah payah didapatkannya adalah kepompong. Jack dan Bekantan keliru saat mengira itu adalah buah, karena saat berada di atas pohon, letak kepompong bersebelahan dengan buah lainnya.

\section{Harga Jual}

Dari awal proses produksi dan sampai tahap akhir dari pembuatan film animasi 2D “Jack The Chicken!” telah dilakuka pendataan biaya, mulai dari biaya tenaga kerja, biaya tidak langsung, dan lain sebagainya. Total dari semua biaya yang 
dikeluarkan dalam pembuatan film animasi "Jack The Chicken!” ini adalah Rp. 14.784.000,- dan dibulatkan menjadi Rp. 15.000.000,-

\section{KESIMPULAN}

Berdasarkan penulisan laporan, berikut adalah kesimpulan yang didapatkan dari seluruh proses pembuatan karya tugas akhir animasi 2D "Jack The Chicken!"

1. Penciptaan Film Animasi 2D “Jack The Chicken!” telah selesai dengan durasi 3 menit 2 detik.

2. Jumlah shot mencapai 47 shot dengan total 3720 frame format HDTC 1920x1080 px 24 fps (frame per second).

3. Penciptaan Film Animasi 2D “Jack The Chicken!” telah membentuk suatu cerita fabel yang berfokus pada salah satu spesies ayam hutan dengan nama latin G. gallus

4. Penciptaan Film Animasi 2D “Jack The Chicken!" menggunakan 12 prinsip Animasi (squash and stretch, anticipation, staging, straight ahead and pose to pose, follow trough and overlapping, slow in and slow out, arcs, secondary action, timing, exaggeration, solid drawing, dan appeal).

\section{SARAN}

Dalam membuat film animasi ini, telah mengalami beberapa hal yang terlah dilalui, hal-hal inilah yang menjadi pelajaran dan dapat menjadi saran yang membangun dan bernilai positif, saran itu antara lain :

1. Menonton film, membaca komik, artikel, dan lain sebagainya merupakan hal penting yang bisa dijadikan referensi dalam membuat cerita. Selain itu, melakukan brainstorming bersama peminat karya seni khususnya film dan animasi akan mempermudah dalam membangun konsep dan cerita dalam membuat film.

2. Melakukan eksplorasi langsung ke lapangan dapat memperkaya referensi dan pengetahuan sebagai dasar penciptaan karya animasi.

3. Riset sangat diperlukan, karena dengan riset dapat membantu dalam membuat konsep karakter, setting tempat, dan lain sebagainya. Riset juga diperlukan agar karya dapat dipertanggungjawabkan dengan benar. 


\section{DAFTAR PUSTAKA}

Chandler, D., \& Munday, R. (2011). A Dictionary of Media and Communication.

Oxford: OUP Oxford. http://doi.org/10.1093/acref/9780199568758.001.0001

Fernandez, I. (2002). Macromedia Flash Animation \& Cartooning: A Creative Guide.

California: McGraw Hill/Osborne.

Nugroho, H. (2011). Pembuatan Model 3D Pesawat Terbang Menggunakan Teknik

NURBS Modeling Pada Software 3D Studio MAX. Sekolah Tinggi Manajemen

Informatika dan Komputer Amikom.

Trapazoid11. (2010). Tak and the Power of Juju - TV Theme Song. Diambil 27

Desember 2018, dari https://www.youtube.com/watch?v=LX8UuEcN8zI

Wing, S. (2011). Les Copaque: Pada Zaman Dahulu animation in Malaysia. Diambil

27 Desember 2018, dari https://www.selinawing.com/2011/11/les-copaque-padazaman-dahulu-animation.html

Wojowasito, S., \& Wasito W, T. (1997). Kamus Lengkap Inggeris-Indonesia IndonesiaInggeris Dengan Ejaan Yang Disempurnakan. Hasta. 
Ari Bakkas Pratama

Film Animasi 2 Dimensi, "Jack the Chicken!"

(HALAMAN INI SENGAJA DIKOSONGKAN) 